\title{
Feridas malignas: uma revisão de literatura
}

\author{
Fungating wounds: a review of the literature
}

\author{
Nadia Antomia Aparecida Poletti, Maria Helena Larcher Caliri, ${ }^{2}$ Cléa D Soares Rodrigues Simão, \\ Karen Bárbara Juliani ${ }^{4}$ e Vivian Ellen Tácito ${ }^{4}$
}

\begin{abstract}
Resumo
0 presente trabalho é uma revisão de literatura, no qual foram analisados doze artigos contendo definição, características e os cuidados com as feridas malignas cutâneas. 0 objetivo foi identificar na literatura quais aspectos estão sendo abordados sobre estas lesões, decorrentes da infiltração de células malignas através do epitélio alterando a integridade epidérmica. Essas feridas possuem características próprias, que são a hemorragia, 0 odor, infecção e exudato. $0 \mathrm{~s}$ apósitos utilizados no tratamento tópico incluem o metronidazol gel, al ginato de cálcio, carvão ativado e hidrogel. Constatamos que, muitas vezes, o tratamento não leva à cicatrização da ferida, uma vez que esta depende do câncer primário. Porém, a cicatrização não é a principal meta do cuidado, mas o controle dos sintomas, visando a uma melhor qualidade de vida aos portadores destas lesões.
\end{abstract}

Palavras-chave: cicatrização de feridas; pele; lesões; neoplasias; cuidados de enfermagem; qualidade de vida.

\section{Abstract}

This paper analysed twelve articles about fungating wounds. It examined the definitions, characteristics and the care. The objective was to identify the aspects of these wounds in the literature. Fungating wounds are the infiltration of malignant cells through the epitelial tissue,changing epidermal integrity. These wounds have their own characteristics such as hemorrhage, smell, infection and exudate. The topic treatment consists on gel metronidazole, calcium alginate, actived charcoal and hydrogel. H owever, generally, this topic treatment doesn't lead to the healing of the wound. It just controls the symptoms, since the cicatrization depends on the primary cancer. The aim of the treatment is to control the symptoms in order to improve the patient's quality of life.

Key words: wound healing; skin; injuries; neoplasms; nursing care; quality of life.

\footnotetext{
${ }^{1}$ Enfermeira. Profa. Curso de enfermagem da Faculdade de M edicina de São José do Rio Preto. Coordenadora do Grupo de Curativos.

${ }^{2}$ Profa. D ra. da Escola de Enfermagem de Ribeirão Preto da U niversidade de São Paulo.

${ }^{3}$ Enfermeira. M estranda pela Escola de Enfermagem de Ribeirão Preto - USP. D ocente da Faculdade de M edicina de São José do Rio Preto. Coordenadora do Grupo de Curativos.

${ }^{4}$ Dicentes do Curso de Enfermagem da Faculdade de M edicina de São José do Rio Preto. Enviar correspondência para K.B.J. Rua Santo Antônio 1856; 15130-000 M arissol, SP - Brasil.

Recebido em dezembro de 2001.
} 


\section{INTRODUÇÃO}

0 presente trabalho emergiu de nossa experiência com o cuidado a pacientes com feridas malignas, durante o estágio extra curricular no grupo de curativos. Intrigava-nos algumas características deste tipo de ferida que as diferenciava das demais.

Iniciamos então uma pesquisa bibliográfica, não sistematizada, sobre o tema, e tivemos uma dificuldade muito grande em encontrar publicações tanto nacionais como internacionais sobre feridas malignas. Para melhor entender estas lesões, apresentaremos a seguir alguns aspectos epidemiológicos do câncer e al gumas características importantes desta doença.

As feridas malignas podem ser originárias de câncer primário na pele ou de metástases. Para o Instituto N acional de Câncer (2000), câncer é o nome dado a mais de 100 doenças que têm em comum 0 crescimento desordenado de células que invadem os tecidos e os órgãos, podendo espal har-se para outras regiões do corpo. Estas célul as dividemse rapidamente, tendendo a ser agressivas e incontroláveis. 0 processo de carcinogênese, ou seja de formação do câncer, em geral se dá lentamente, podendo levar vários anos para que uma célula cancerosa prolifere e dê origem a um tumor visível. Esse processo passa por vários estágios antes de chegar ao tumor.

As células alteradas passam então a se comportar de forma anormal. M ultiplicamse de maneira descontrolada, mais rapidamente do que as células normais do tecido à sua volta, invadindo-o. Geralmente, têm capacidade para formar novos vasos sanguíneos que as nutrirão e manterão as atividades de crescimento descontrolado. 0 acúmulo dessas células forma os tumores malignos. ${ }^{1}$

Estas células têm a capacidade de se desprender do tumor e de migrar. Invadem inicialmente os tecidos vizinhos, podendo chegar ao interior de um vaso sangüíneo ou linfático e, através desses, disseminar-se, chegando a órgãos distantes do local onde 0 tumor se iniciou, formando as metástases. D ependendo do tipo da célula do tumor, alguns dão metástases mais rápido e mais precocemente, outros o fazem bem lentamente ou até não 0 fazem. ${ }^{2}$

O câncer, segundo o IN CA (2000), é a segunda doença que mais leva a óbitos no Brasil, sendo que no ano de 1997, 106.990 pessoas foram a óbito por algum tipo de câncer. Estima-se que no ano 2000 haverá 284.205 novos casos de câncer no país. As principais causas de todos esses óbitos são 0 diagnóstico incorreto do câncer, falta de tratamento, encaminhamentos inadequados e desinformação dos médicos, combinados ao pavor que a doença causa e ao estigma histórico. Atualmente quando o câncer é diagnosticado precocemente (grau zero de estadiamento) a cura pode atingir $96,5 \%{ }^{3}$

$\mathrm{N}$ este contexto, um problema que tem se tornado cada vez mais comum, são as feridas dérmicas provocadas pelo câncer, que também são denominadas de feridas malignas. Assim optamos por realizar uma revisão sistematizada de literatura relacionada ao assunto em questão para identificar, quais os aspectos abordados pelos autores sobre feridas malignas.

\section{MÉTODOS}

Para atingir os objetivos propostos, realizamos uma revisão da literatura, por entendermos que o cuidado a feridas malignas é um tema relevante para a enfermagem. $\mathrm{A}$ revisão de literatura é descrita como a busca de informações sobre um tema ou tópico que resuma a situação dos conhecimentos sobre um problema de pesquisa. 0 principal objetivo da revisão de literatura é fornecer uma síntese dos resultados de pesquisa, para auxiliar o profissional a tomar decisões. N este tipo de estudo são abordados os tópicos relevantes sobre o tema, de forma a proporcionar ao leitor uma compreensão do que existe publicado sobre 0 assunto. Assim a revisão tem uma função integradora e facilita 0 acúmulo de conhecimento. ${ }^{4}$

\section{IDENTIFICAÇÃO DAS FONTES BIBLIOGRÁFICAS}

$\mathrm{N}$ a identificação das fontes bibliográficas foram utilizadas três bases de dados. Para identificar a literatura nacional foi consultada a base de dados LILACS, para a identificação da literatura internacional foram consultadas as bases de dados Comprehensive $M$ edline $\mathrm{e}$ 
CINAHL.

Para identificar as publicações indexadas nesta base de dados foram, utilizadas as seguintes palavras chaves: "malignant wound", "fungating wound" e"feridas malignas".

\section{TIPO DE ESTUDO, AMOSTRA E LOCAL}

Trata-se de uma revisão de literatura onde levantamos 12 publicações referentes aos cuidados com os pacientes portadores de feridas malignas cutâneas.

Quanto ao tipo de publicação, foram considerados apenas os periódicos; em relação à procedência fizeram parte da amostra periódicos nacionais e internacionais publicados em português e inglês. 0 estudo foi realizado em uma escola de enfermagem estadual do interior de estado de São Paulo que também desenvolve pesquisas.

\section{COLETA DE DADOS}

D efinida a amostra do estudo, realizamos a coleta de dados, visando a identificar os aspectos relevantes do tema e os itens de análise. Para tanto utilizamosum instrumento, que foi, elaborado por Poletti eC aliri $^{5}$ em uma dissertação de mestrado sobre feridas crônicas, adaptado do modelo originalmente sugerido por Ganong. ${ }^{6}$

\section{ANÁLISE DOS DADOS}

Os dados foram analisados segundo um formulário e atendeu os seguintes critérios: dados de identificação dos autores e dos artigos, o ano de publicação, título e periódico, declaração dos objetivos e análise do conteúdo quanto ao tipo de ferida, tratamento e assistência de enfermagem.

\section{RESULTADOS E DISCUSSÃO}

A análisedos dados demandou um trabalho de leitura de todos os artigos. D os 12 artigos localizados, 11 eram em inglês e um artigo em língua portuguesa. $\mathrm{Na}$ Tabela 1 apresentamos a listagem dos artigos segundo 0 ano de publicação, autor, título e periódico.
Tabela 1. Listagem dos artigos analisados segundo o autor e ano de publicação, título, periódico e número.

\begin{tabular}{|c|c|c|c|}
\hline$A \cap 0$ & Autor & Titub & Peribdico, vol గr. \\
\hline $\begin{array}{l}1990 \\
1991\end{array}$ & $\begin{array}{l}\text { NETK } \\
\text { HERL }\end{array}$ & $\begin{array}{l}\text { Fungating and uke ating malignant } \\
\text { lesiors: review of the lite rature } \\
\text { Treating fungating ksiors }\end{array}$ & $\begin{array}{l}\text { J.Adv Hurs v.43, ח.4 } \\
\text { Murs.Times v.87,ח.ろ }\end{array}$ \\
\hline $\begin{array}{l}1992 \\
1993\end{array}$ & $\begin{array}{l}\text { SाTOH } \\
\text { GROCOT }\end{array}$ & $\begin{array}{l}\text { Early and late. radiation induced shin } \\
\text { alte ratio r } \\
\text { Pratical charges }\end{array}$ & $\begin{array}{l}\text { Oncology Hurs } \\
\text { v.19, } 6.6 \\
\text { Hurs Times v.89,ח.7 }\end{array}$ \\
\hline 1994 & $\begin{array}{l}\text { UPRIGHT } \\
\text { WHEDOH }\end{array}$ & 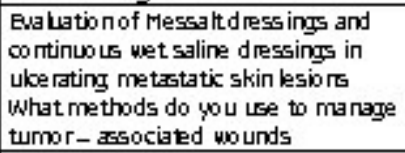 & $\begin{array}{l}\text { Cancerkurs v.17,n.Z } \\
\text { Oncology Murs Forum } \\
\text { v.ZZ, ח.6}\end{array}$ \\
\hline $\begin{array}{l}1995 \\
1997\end{array}$ & \begin{tabular}{|l} 
HAUET \\
COSSROVE
\end{tabular} & $\begin{array}{l}\text { Fungating wounds } \\
\text { Faith Healing }\end{array}$ & \begin{tabular}{|l} 
Hurs Times v.91, ח.39 \\
Hurs Times ט. $93, \pi .7$ \\
\end{tabular} \\
\hline $\begin{array}{l}1997 \\
1997\end{array}$ & $\begin{array}{l}\text { HAEFIELD } \\
\text { SRUMDERS }\end{array}$ & $\begin{array}{l}\text { Malgna ntc utaneous wounds: a } \\
\text { managem. protocol } \\
\text { Mutulal support }\end{array}$ & $\begin{array}{l}\text { Ostomingound Marag } \\
\text { v.43, n.1 } \\
\text { Hurs Times v. 9Z, ח.3Z }\end{array}$ \\
\hline 1999 & AHORIM & $\begin{array}{l}\text { nore letive de brid me nta and } \\
\text { antimicm bialc learsing of a venting } \\
\text { ductal breatcarcinoma } \\
\text { Lesoes axtlnicas em pele }\end{array}$ & $\begin{array}{l}\text { Arch Phys Med } \\
\text { Fetabil v.80.jn } \\
\text { Rev.Esc. Enf.uSp } \\
\text { v.esp }\end{array}$ \\
\hline
\end{tabular}

O bserva-se neste quadro que um maior número de publicações sobre feridas malignas ocorreu a partir do ano de 1995. Este aumento se deve provavelmente à crescente preocupação com o cuidado a estas lesões e ao aumento da expectativa de vida dos pacientes, que está vinculado aos avanços, terapêuticos e à expectativa de vida de pacientes portadores de doenças de caráter maligno.

Q uanto à profissão dos autores 11 são enfermeiros e um é fisioterapeuta; em relação ao país de origem, $42 \%$ são da Inglaterra, $42 \%$ dos EUA, 8\% do Canadá e $8 \%$ do Brasil.

Apresentaremos a seguir uma análise qualitativa dos artigos segundo o objetivo traçado neste trabalho

\section{FERIDAS MALIGNAS: DEFINIÇÃO E CARACTERÍSTICAS}

As feridas malignas cutâneas são definidas como resultado da infiltração do câncer no epitélio, e são ricamente vascularizadas com vasos sanguíneos e linfáticos. ${ }^{7,8}$

São definidas ainda como a quebra da integridade epidérmica por infiltração das células malignas, sendo que $5 \%$ a $10 \%$ das pessoas com câncer desenvolvem mestátases para a pele durante os seis últimos meses de vida. As metástases cutâneas ocorrem com maior freqüência por via linfática, corrente sanguínea ou diretamente da lesão primária, podendo ocorrer também na linha de sutura após cirurgia de tumor primário ou de câncer recorrente..$^{9,10}$ 
As feridas malignas cutâneas podem ser reconhecidas devido a sua semelhança com infecções dérmicas por fungos, podendo inicialmente apresentar-se como nódulos ou como uma cratera ulcerativa resultante de um câncer ignorado, comumente associado com carcinoma de células escamosas ou melanoma. Inicialmente o tumor maligno pode se apresentar como uma ou várias feridas que não cicatrizam. A coloração pode variar, muitas apresentam a mesma cor da pele e outras variam de rósea, vermelho, violeta ou marrom. ${ }^{9}$

Além de não cicatrizarem, outras características importantes observadas neste tipo de ferida são o sangramento, a exsudação intensa e a presença de um odor característico. A seguir apresentamos a fisiopatologia que fundamenta estas condições segundo os autores revisados.

A função das plaquetas é anulada pela células tumorais; estas estimulam a produção de fatores de crescimento específicos, acarretando danos às células normais. D este modo o tumor cresce e aumenta sua rede neovascular, ocorrendo assim uma pressão sobre o tecido, levando a um desequilíbrio fisiológico que provoca o sangramento das células e, conseqüentemente, a ferida também sangra. As grandes hemorragias são causadas por rupturas dos principais vasos situados no tumor; além destas rupturas, o sangramento também ocorre devido a tratamentos como a radioterapia, e por traumas durante a remoção do curativo

A oclusão dos vasos sanguíneos (devido à pressão causada, pelo crescimento do estroma tumoral) tem como resultado a redução na difusão do oxigênio, o que provoca hipóxia. Assim, bactérias aeróbias e, principalmente, anaeróbias produzem odor fétido devido a liberação de ácidos voláteis. ${ }^{7-9,11}$

\section{TRATAMENTO E TERAPIA TÓPICA}

0 cuidado do paciente com este tipo de lesão deve prever não somente o controle de sintomas físicos mas também dos problemas psicossociais. Estas feridas tem um grande impacto sobre 0 paciente não apenas pelas alterações físicas que podem causar, mas sobretudo pelo estigma que ainda existe em relação ao prognóstico do câncer. A avaliação é um componente essencial para identificar o indivíduo e suas angústias. Isso ajuda a garantir um cuidado mais apropriado ao paciente. Alguns aspectos que devem ser levados em consideração durante a avaliação, incluindo história, a causa e o estágio da doença, avaliação nutricional, tratamentos presentes, considerações emocionais, mudança da auto-imagem, conhecimento do diagnóstico, a influência da família no cuidado, o sistema de avaliação e o local da ferida associado aos sintomas. ${ }^{7}$

A radioterapia é um dos tratamentos de primeira escolha para redução da sintomatologia. Ela destrói as células tumorais, pela radiação, diminuindo o tamanho da lesão, o exsudato, 0 sangramento, proporcionando maior conforto ao paciente. Por outro lado, com o avançar do tratamento podem ocorrer ulcerações em decorrência da radioterapia. ${ }^{7,11}$

O utro tratamento de primeira escolha é a quimioterapia, que reduz o tumor e melhora a dor, porém aumenta o risco de hemorragia. A hormonioterapia ajuda a reduzir os sintomas do paciente com tumores sensíveis, como o de mama. 0 tratamento a laser pode levar à redução da dor e da necrose tissular.

A terapia tópica da ferida é um aspecto importante do tratamento onde devem ser consideradas as características peculiares da ferida. Se a ferida apresenta sangramento, 0 alginato de cálcio é um produto que tem sido muito utilizado. Este apósito que é um derivado de algas marrons, tem concentrações aumentadas de cálcio queativam o mecanismo de coagulação, fazendo trocas com os íons sódio do exsudato eformando um gel viscoso, sendo menos lesivo para a ferida durante a remoção. 0 uso de adrenalina no leito da ferida também éindicado se houver sangrento local persistente. São também utilizados produtos hemostáticos como o óxido de celulose e, persistindo o sangramento e a coagulação não ocorrer apesar do tratamento, o paciente deverá ser levado à sutura ou cauterização. ${ }^{7,11}$

O controle do exsudato é importante devido a vários fatores, tais como a diminuição do odor, aumento do conforto do paciente e melhora da auto estima. Embora o controle possa ser difícil, o uso do alginato 
de cálcio ou substâncias semipermeáveis é recomendado para o curativo oclusivo. 0 alginato de cálcio tem um grande poder de absorção do exsudato, além de moldar-se bem à ferida e propiciar maior conforto ao paciente. ${ }^{7,12}$

A infecção da ferida por microorganismos anaeróbios e tecido desvitalizado causa o odor e a infecção. Quanto ao tratamento para infecção, é usado um antibiótico sistêmico para reduzir as colônias de microorganismos do tecido necrótico e infecção por anaeróbios, o que conduz à redução do odor. N o controle do odor é recomendável a aplicação de metronidazol gel ou solução, sobre o leito da ferida, pois o seu mecanismo de ação neste caso ocorre diretamente sobre os microorganismos an aeróbios responsáveis pela produção de ácidos voláteis causadores do odor. $^{13}$

0 carvão ativado éum tratamento paliativo no controle do odor. É um produto estéril composto por uma cobertura de contato de baixa aderência, constituída por uma camada de rayon e uma almofada central impregnada por carvão ativado e prata a 0,15\% . 0 carvão ativado adsorve os gases liberados pelos microorganismos, o exsudato produzido e filtra o odor, sendo que a prata tem uma ação bactericida. É indicado em feridas fétidas, infectadas e exsudativas, sendo necessária a utilização de um curativo secundário que deve ser trocado sempre que estiver saturado. ${ }^{11}$

0 uso de anti-sépticos é algumas vezes indicado para a diminuição do odor. 0 hipoclorito de sódio $0,25 \%$ é uma das melhores alternativas para dissolver o tecido necrótico. Pode ser usado tanto para irrigação como para aplicação, sobre o leito da ferida. É utilizado freqüentemente para 0 desbridamento superficial da lesão, E o uso deve ser interrompido se, ao se limpar a lesão, houver sangramento ou irritação. Em pacientes que apresentam sensibilidade a este produto, o mesmo deve ser substituído pelo gluconato de clorexidina 4\% emulsão ou solução aquosa a 1\%. Embora existam diversos tipos de tratamento, com a evolução da doença torna-se cada vez mais difícil o controle do odor. ${ }^{15,17}$

A margem da ferida e a pele perilesional freqüentemente precisam de proteção devido ao exsudato drenado, pois pode ocorrer maceração da pele ao redor da ferida e rompimento da barreira de proteção. $G$ randes benefícios têm sido relatados com aplicação de vitamina $A+D$ em pomada. 0 tecido friável da margem da ferida precisa ser protegido e então deve-se aplicar uma barreira úmida que ajude a prevenir macerações na borda, que consiste na aplicação de vitamina A tópica que estimula a reepitelização rápida.

Produtos conservadores de umidade como os lubrificantes são recomendados no tratamento preventivo do prurido erachadura da pele seca. Os esteróides a $1 \%$ são indicados para aliviar o prurido. Estes produtos podem ser prescritos de três a quatro vezes ao dia, evitando-se usar três a quatro horas antes do tratamento com radiação. Já as áreas afetadas por descamação úmida, convém ocluí-las emanter 0 ambiente úmido com hidrogel que é um gel composto por água $(77,7 \%)$, carboximetilcelulose $(2,3 \%)$ e propilenoglicol $(20 \%))^{11}$

A dor é um outro aspecto importante e tem origem no crescimento tumoral e nos traumas provocados pelos curativos inadequados. 0 desconforto e a dor deste tipo de ferida vão depender da localização, envolvimento de nervos e dos danos causados ao tecido. Para tanto é necessária uma avaliação rigorosa, para a escolha adequada do curativo que reduza os traumas e a dor durante a remoção. U m curativo que mantenha meio úmido na ferida, reduz o número de trocas de curativo minimizando a dor e o desconforto. 0 uso de gel anestésico como tricíclicos e corticóides sobre o leito da ferida pode reduzir a dor associado a escoriações e infecções da pele perilesional. ${ }^{16,18}$

É importanteque a família esteja envolvida com o tratamento, pois juntos poderão tomar decisões para melhorar a qualidade de vida do paciente. A ajuda da família deve ser considerada principalmente se 0 paciente optar pelo tratamento domiciliar. O utro aspecto que deve ser considerado é a nutrição, devendo ser estimulada a suplementação de proteínas e sais minerais pela necessidade de reposição de fluidos. ${ }^{7}$

Verificamos ainda nas publicações 
analisadas a utilização de um protocolo para cuidado de feridas malignas cutâneas. Este protocolo aborda quatro itens importantes: a) aval iação da evolução da ferida; b) utilização de produtos adequados; c) avaliação psicossocial; d) ensino do cuidado ao paciente e familiares.

A avaliação da ferida deve considerar 0 tamanho, área envolvida, a cor, o odor, 0 exsudato, o sangramento, o prurido e a descamação. Q uanto à avaliação do paciente, ela deve envolver a questão emocional a autoestima o autocuidado e a disponibilidade financeira para o tratamento. O s cuidados básicos consistem na limpeza da ferida, controle do exsudato, remoção das áreas de tecido desvitalizado e manutenção do ambiente úmido, ${ }^{9,10}$

$\mathrm{N}$ este mesmo protocolo verifica-se que houve uma preocupação dos autores com 0 cuidado específico para cada sintoma. 0 odor deverá ser tratado através do controle do exsudato, e nas feridas altamente exsudativas devem ser utilizados curativos absorventes. $\mathrm{N}$ as áreas de tecido desvitalizado deve-se usar produtos para o desbridamento autolítico. 0 controle do sangramento na remoção do curativo deve ser feito através da umidificação prévia e remoção cautelosa. ${ }^{17}$

Para controlar os grandes sangramentos indica-se 0 nitrato de prata, cauterização e curativos hemostáticos. $\mathrm{N}$ a realização do curativo deve-se tomar o cuidado de não alterar a auto-imagem do paciente, mantendo a estética e o conforto. 0 local com infecção deve ser irrigado constantemente, desbridado e aplicá-lo antibiótico tópico. 0 prurido pode ser controlado com o uso de antiinflamatório não esteróides ou creme tópico. A administração de medicamentos anestésicos gel ou spray no local da lesão antes da remoção do curativo é excelente na prevenção na dor. A pós todos estes procedimentos deve-se fazer a documentação através da anotação de enfermagem.

\section{CONSIDERAÇÕES FINAIS}

Através deste trabalho tivemos a oportunidade de entender que as feridas malignas cutâneas são resultado da infiltração de células malignas para o epitélio que leva à quebra da integridade epidérmica, e podem ser decorrentes de metástase por via linfática, sanguínea ou diretamente do tumor primário.

Entendemos que essas feridas possuem características próprias, que são a hemorragia, o odor, a infecção e o exsudato, que deverão ser tratados com os diferentes produtos existentes hoje no mercado como al ginato de cálcio, carvão ativado, hidrogel, metronidazol. Também produtos como hipoclorito e cloroexidina ainda são indicados e utilizados para diminuir o odor muitas vezes presente, especialmente neste tipo de ferida, porém devem ser utilizados com critério.

E finalmente constatamos que, muitas vezes, o tratamento não leva à cicatrização da ferida, pois tal depende do câncer primário. A evolução da cicatrização está relacionada à involução da patologia primária, mas mesmo assim é importante o controle dos sintomas para melhorar a qualidade de vida desses pacientes.

As reações dos profissionais frente à ferida são muito importantes, especialmente, sinais não verbais, como expressões faciais frente a lesão e o odor. É importante envolver 0 paciente em todas as decisões sobre seu tratamento, isso pode promover um relacionamento baseado na confiança. 0 paciente precisa ser avaliado em todos os seus aspectos para que ocorra a restauração da harmonia entre corpo, mente e espírito que é a essência do cuidado holístico.

\section{REFERÊNCIAS BIBLIOGRÁFICAS}

1. Smeltzer SC, BareBG. Tratado deenfermagem médico cirúrgica. 8a ed. Rio de Janeiro: Guanabara K oogan;1998.

2. RobbinsLS. Patologia estrutural funcional. $5 a$ ed. Rio deJ aneiro: G uanabara Koogan; 1996.

3. C aversan $L$. D iagnóstico falho reduz a cura do câncer. Folha deSão Paulo 2000 jun 11.

4. Polit D F, H ungler BP. Fundamentos dapesquisa em enfermagem. $3 a$ ed. Porto Alegre: Artes M édicas; 1995.

5. Poletti NAA, Caliri MH. O cuidado de enfermagem a pacientescom feridas crônicas: a busca de evidência para a prática [dissertação]. Ribeirão Preto: Escola de Enfermagem de Ribeirão Preto daU niversidadedeSão Paulo; 2000. $245 p$. 
6. Ganong LH . Integrative review of nursing research. Res N urs H ealth 1987;10:1-11.

7. Hallet $A$. Fungating wound. $N$ urs Times 1993;91(39):81-5.

8. Grocott P. Wound care- pratical changes. N urs Times 1993;89(7):64-70.

9. H aisfield-Wolfe M E, R und C. M alignant Cutaneous wound: a management protocol. Ostomy Wound M anage 1997;43(1):56-66.

10. Amorin EF. Lesões actinicas em pele. Rev Esc Enf U SP1999;33(N úmero Especial).

11. Whedon M A. W hat methods do you use to managetumor- associated wounds. O ncol N urs Forum 1995;22(6):987.

12. Saunders $S$. Mutual support. Nurs Times 1997;92(32):76-82.

13. Yvetic 0 , Line PA. Fungating and ulcerating malignat lesions: review of theliterature.

J Adv N urs 1990;15:83-8.

14. Cosgrove $S$. Faith healting. Wound $C$ are 1997;93(7):57-66.

15. N eal $K$. Treating fungating lesions. N ursT imes 1991;87(23):85-6.

16. Sitton E. Early and late: radiation induced alterations. Oncol Nurs Forum 1992;19(6): 907-12.

17. N ash M S, N ash LH , G arcia RG, N eimark P. $\mathrm{N}$ onselective debridement and antimicrobial cleansing of a venting ductal breast carcinoma. Arch Phys Rehabil 1999;80(1):118-21.

18. Upright AC, Salton C, Roberts F, M urphy J. Evaluation of $M$ esalt dressing and continuous wet salinedressing in ulcerating metastatic skin lesions. C ancer N urs 1994;17(2):149-55. 